\title{
Influence of wear on the performance of 2-lobe slot entry hybrid journal bearings
}

\author{
Prashant B. Kushare and Satish C. Sharma \\ Department of Mechanical and Industrial Engineering, Tribology Laboratory, Indian Institute of Technology, \\ 247667 Roorkee, India
}

Received 9 November 2014, Accepted 12 March 2015

\begin{abstract}
In the present paper, the influence of wear on the performance of 2-lobe slot entry restrictor bearing has been investigated theoretically. The equation of fluid flow field has been solved by using Galerkin's technique of FEM. In this study, Dufrane's wear model has been used to consider the change in bush geometry due to wear. The performance of 2-lobe slot entry restrictor bearing is studied for both symmetric and asymmetric slot configurations. The simulated results of the study indicate that the wear defect substantially changes the performance of 2-lobe slot entry journal bearing systems. A proper choice of bearing geometry and bearing configuration (12 slots and 6 slots per row) may partially compensate the loss occurred due to wear.
\end{abstract}

Key words: 2-lobe / wear / slot entry / hybrid / journal bearing

\section{Introduction}

Extensive advantages of circular hybrid journal bearings in various industrial applications have been reported in published literature [1-10]. However, the wide applicability of recessed hybrid journal bearing is somewhat restricted due to generation of less hydrodynamic action as less land area is available [5]. This leads to the development of non-recessed journal bearings. In recent times, the non-recessed hydrostatic/hybrid bearings have found employed in various engineering applications such as high speed turbo machinery, machine tool spindles, precision grinding spindles, reactor coolant pumps, rocket engines and test equipments etc. A slot entry non-recessed bearing is one of the most preferred non-recessed journal bearing configuration over the recessed because of its improved fluid film stiffness and film damping characteristics. One of the main application of slot entry bearing is for grinding wheel spindles where gas bearings tend to be used for lightly loaded spindles and liquid bearing for heavily loaded applications $[1,3,4]$. As a consequence of this, many studies related to the performance of slotentry circular journal bearings have been reported in the literature [3-10].

Shires and Dee [1] were the first ones to develop the slot-entry journal bearing configuration. They dealt with the problem of gas dispersion encountered because of orifice restrictor by inventing the concept of slot entry re-

${ }^{a}$ Corresponding author: pbkushare@gmail.com strictor. Further, consequential detailed studies of various aspects of slot entry hybrid journal bearing were carried by Rowe et al. [3-6]. Further, comparative studies with recessed and axial groove hydrodynamic were presented Rowe et al. [5]. They reported the advantages of slot entry bearing over recessed and hydrodynamic journal bearing. Theoretical analyses of slot-entry non-recessed bearings in turbulent regime are also presented by Ives and Rowe [6] by using the Finite Difference Method. Experimental investigation of comparative study of effect of different restrictors on hybrid journal bearing performance, including double row slot entry was reported by Shangxian Xu [7]. The results of experimental studies confirmed the validity of theoretically computed results. Sharma et al. [8-10] thoroughly investigated the influence of bearing flexibility and micropolar fluid on the performance of circular slot entry hybrid journal bearing by using Finite Element Method.

Recently, many bearing designers have focused their attention towards lobed journal bearings owing to their excellent dynamic performance and better anti-whirl characteristics over circular journal bearings. A 2-lobe journal bearing is one of the most adopted multilobe bearing configurations used in high speed rotary machines. As a result of this, enormous theoretical and experimental studies related to multilobe bearing geometries have been reported in the literature [11-21]. As the noncircular bearings having 2-lobe, 3-lobe and 4-lobes, is known to exhibit better anti whirl characteristics. This feature 


\section{Nomenclature}

\begin{tabular}{|c|c|}
\hline$a_{\mathrm{b}}$ & Bearing land width, $\mathrm{m}$ \\
\hline$a_{\mathrm{s}}$ & Extent of slot, $\mathrm{m}$ \\
\hline$c$ & Radial clearance, $\mathrm{m}$ \\
\hline$C_{1}$ & Clearance due to circumscribed circle on the bearing, $m$ \\
\hline$C_{2}$ & Clearance due to inscribed circle on the bearing, $m$ \\
\hline$D$ & Journal diameter, $\mathrm{m}$ \\
\hline$e$ & Journal eccentricity, m \\
\hline$E$ & Young's modulus of elasticity, $\mathrm{Pa}$ \\
\hline$F$ & Fluid film reaction $(\partial h / \partial t \neq 0), \mathrm{N}$ \\
\hline$F_{x}, F_{z}$ & Components of fluid film reactions in $X$ and $Z$ direction $(\partial h / \partial t \neq 0), \mathrm{N}$ \\
\hline & Fluid film reaction $(\partial h / \partial t=0), \mathrm{N}$ \\
\hline$g$ & Acceleration due to gravity, $\mathrm{m} . \mathrm{s}^{-2}$ \\
\hline$h$ & Nominal fluid-film thickness, $\mathrm{m}$ \\
\hline$L$ & Bearing length, $\mathrm{m}$ \\
\hline$n$ & Number of rows of slots \\
\hline$p$ & Pressure, $\mathrm{Pa}$ \\
\hline$Q$ & Bearing flow, $\mathrm{m}^{3} \cdot \mathrm{s}^{-1}$ \\
\hline$R_{\mathrm{j}}, R_{\mathrm{L}}, R_{\mathrm{b}}$ & Radius of journal, lobe and bearing, $\mathrm{m}$ \\
\hline$S_{i j}$ & Stiffness coefficients $(i, j=1,2), \mathrm{N}^{-1} \mathrm{~m}^{-1}$ \\
\hline$C_{i j}$ & Damping coefficients $(i, j=1,2)$, N.s.m $^{-1}$ \\
\hline$t$ & Time, s \\
\hline$\omega_{I}$ & $(g / c)^{1 / 2}, \operatorname{rad}_{.} \mathrm{s}^{-1}$ \\
\hline$W_{o}$ & External load, N \\
\hline$Y_{\mathrm{s}}$ & Radial length of slot, $\mathrm{m}$ \\
\hline$Z_{\mathrm{s}}$ & Axial width of slot, $\mathrm{m}$ \\
\hline$X, Y, Z$ & Cartesian coordinates \\
\hline$X_{j}, Z_{j}$ & $\begin{array}{l}\text { Coordinates of steady state equilibrium journal } \\
\text { center from geometric center of bearing, m }\end{array}$ \\
\hline \multicolumn{2}{|r|}{ Greek symbols } \\
\hline$\lambda=L / D$ & Aspect ratio \\
\hline$\varphi$ & Attitude angle of tact bearing \\
\hline$\varphi_{\mathrm{w}}$ & Attitude angle worn bearing \\
\hline$\rho$ & Density of the lubricant $\mathrm{kg} \cdot \mathrm{m}^{-3}$ \\
\hline$O_{j}, O_{L i}$ & Journal Centre, Lobe centre \\
\hline$\omega_{\mathrm{j}}$ & Journal rotational speed, rad.s ${ }^{-1}$ \\
\hline$\omega_{\text {th }}$ & Threshold speed, rad.s ${ }^{-1}$ \\
\hline$p_{\mathrm{s}}$ & Lubricant supply pressure, $\mathrm{Pa}$ \\
\hline$\delta_{\mathrm{w}}$ & Wear depth, m \\
\hline$\Omega$ & Speed parameter \\
\hline$\beta^{*}$ & Concentric design pressure ratio \\
\hline$\alpha_{b}$ & Start of the worn region \\
\hline$\alpha_{\mathrm{e}}$ & End of the worn region \\
\hline$\delta$ & Offset factor \\
\hline$\varepsilon$ & Eccentricity ratio \\
\hline \multicolumn{2}{|r|}{ Non-dimensional parameters } \\
\hline $\bar{a}_{\mathrm{b}}=a_{\mathrm{b}} / L$ & Land width ratio \\
\hline$\beta^{*}=p^{*} / p_{\mathrm{s}}$ & Concentric design pressure ratio \\
\hline $\bar{C}_{S R}=\frac{\pi}{36} \frac{S W R}{\lambda} \frac{k}{\bar{a}_{\mathrm{b}}} \frac{a_{\mathrm{b}}}{Y_{\mathrm{S}}}\left[\frac{Z_{\mathrm{s}}}{c}\right]^{3}$ & Restrictor design parameter \\
\hline$S W R=a_{\mathrm{s}} /\left(a_{\mathrm{s}}\right)_{\mathrm{b}} Y_{\mathrm{s}}$ & \\
\hline $\bar{C}_{i j}=C_{i j}\left(c^{3} / \mu R_{j}^{4}\right)$ & \\
\hline$\left(\bar{F}, \bar{F}_{0}\right)=\left(F, \bar{F}_{o}\right) / p_{s} R_{j}^{2}$ & \\
\hline$(\bar{h})=(h) / c$ & \\
\hline $\bar{p}, \bar{p}_{\mathrm{c}}, \bar{p}_{\max }=\left(p, p_{\mathrm{c}}, p_{\max }\right) / p_{s}$ & \\
\hline $\begin{array}{l}\bar{Q}=Q\left(\mu / c^{3} p_{s}\right) \\
\bar{S}_{i j}=S_{i j}\left(c / p_{s} R_{i}^{2}\right)\end{array}$ & \\
\hline$S_{i j}=S_{i j}\left(c / p_{s} R_{j}^{2}\right)$ & \\
\hline
\end{tabular}




\begin{tabular}{|c|c|}
\hline $\begin{array}{l}\bar{W}_{0}=W_{0} / p_{s} R_{j}^{2} \\
\left(\bar{X}_{j}, \bar{Z}_{j}\right)=\left(X_{j}, Z_{j}\right) c \\
\bar{X}_{L}^{i}, \bar{Z}_{L}^{i}=\left(X_{L}^{i}, Z_{L}^{i}\right) / \\
t=t\left(c^{2} p_{\mathrm{s}} / \mu R_{j}^{2}\right) \\
\varepsilon=e / c \\
\bar{\delta}_{\mathrm{W}}=\delta_{\mathrm{W}} / c \\
\delta=C_{1} / C_{2} \\
\bar{\omega}_{\mathrm{th}}=\omega_{\mathrm{th}} / \omega_{I} \\
\Omega=\omega_{J}\left(\mu R_{j}^{2} / c^{2} p_{\mathrm{s}}\right)\end{array}$ & Speed parameter \\
\hline \multicolumn{2}{|r|}{ Matrices } \\
\hline $\begin{array}{l}N_{i}, N_{j} \\
{[\bar{F}]} \\
\{\bar{p}\} \\
\{\bar{Q}\} \\
\left\{\bar{R}_{H}\right\} \\
\left\{\bar{R}_{X j}\right\},\left\{\bar{R}_{Z_{j}}\right\}\end{array}$ & $\begin{array}{l}\text { Shape functions } \\
\text { Assembled Fluidity matrix } \\
\text { Nodal pressure vector } \\
\text { Nodal flow vector } \\
\text { Column due to hydrodynamic terms } \\
\text { Global right hand side vector due } \\
\text { to journal center velocities. }\end{array}$ \\
\hline \multicolumn{2}{|c|}{ Subscripts and Superscripts } \\
\hline$b$ & Bearing \\
\hline$J$ & Journal \\
\hline$R$ & Restrictor \\
\hline$s$ & Supply \\
\hline$L$ & Lobe \\
\hline$i$ & Lobe number \\
\hline $\min$ & Minimum \\
\hline $\max$ & Maximum \\
\hline$\cdot$ & First derivative w.r.t time \\
\hline * & Concentric operation \\
\hline- & Corresponding \\
\hline & non-dimensional parameter \\
\hline
\end{tabular}

may make them suitable to be used in many applications such as high speed turbo machinery. Therefore, to harness advantages of lobed bearing geometry and slot entry bearing configuration in a single configuration, a novel 2-lobe slot entry bearing configuration is proposed to be studied. Similar studies in case of recessed bearing have already been reported by Ghosh and Satish [15,16] and Phalle et al. [18].

Further, during the operation of the machine, the bearing is subjected to numerous start and stop operations leading to progressive abrasive wear of bearing surface. Consequently, wear occurs and bearing bush geometry gets changed. It affects the static and dynamic performance of the bearing system. In hybrid journal bearings also wear occurred because of several start and stop operations regardless of the presence of lift-pump systems. Therefore, to design bearing more accurately and to generate realistic bearing characteristics data, the wear must be considered in the analysis. Many studies, both experimental and analytical concerning the worn hydrodynamic journal bearings and recessed hybrid journal bearings reported and described in the literature [2229]. A very few studies of worn non-recessed hydrostatic/hybrid journal bearings are also available in the published literature [20,21]. The first study of bearing surface wear damage of hydrostatic journal bearings was carried out by Redcliff and Vohr [26]. They presented an analytical and experimental investigation of hydrostatic bearings used in high-pressure, cryogenic rocket engine turbo pumps. In this experimental investigation, they reported that the occurrence of wear on bearing surface by ten percentage of radial clearance took place after ten start/stop operations. Tokar and Alexandrov [27] theoretically investigated the performance of worn hydrostatic journal bearings using a FEM. Dufrane et al. [22] studied the occurrence of wear in turbo-generator hydrodynamic journal bearing. It was observed that the occurrence of wear due to several start/stop operations, crops up at the bottom of bearing surface. They have modeled the footprint of a worn segment. Further, they validated the wear model with the experimental data. Afterward several studies [2, 23-25, 29] based on Dufrane model have been carried out and presented by many investigators. Fillon and Bouyer [25] carried out thermohydrodynamic study of worn journal bearing system and reported that Dufrane model provides the best approximation with the experimental results of wear study. Further, Bouyer et al. [19] carried out an experimental and theoretical study of worn 2-lobe plain journal bearing. Recent study of Phalle et al. [18] indicates that worn out of bearing surface which is more than $30 \%$ of radial clearance significantly affects the bearing performance. They also reported that influence of wear defect can be minimized by choosing appropriate bearing geometry. Recently, Kushare and Sharma [21,22] studied the influence of cubic law lubricant on the performance of two lobe worn hole entry journal bearing system. Further, they presented the nonlinear transient stability response of the symmetric worn bearing configuration. It has been concluded from the study that there is a substantial decrease in the value of the direct rotor dynamic coefficient by 18 $30 \%$ for worn bearing operated with cubic law lubricant.

A thorough survey of literature reveals that the influence of wear defect significantly changes the performance characteristics of worn circular hybrid journal bearing. To the best of the author's knowledge, no study has yet been reported for the case of slot entry bearings.

The present study is therefore aimed to bridge the gap in literature. In the present work a novel bearing configuration of slot entry bearing having 2-lobes is proposed to be studied. Further, the influence of wear on the performance of 2-lobe slot entry symmetric and asymmetric journal bearing system is also investigated. The study also compares the performance of circular slot entry and 2-lobe slot entry bearing w.r.t. $\bar{h}_{\min } \bar{S}_{22}, \bar{C}_{22}$ and $\bar{\omega}_{\text {th }}$ so that the bearing designer may choose a suitable configuration. The computed results of the study are expected to be quite useful to the bearing designers and to the academic community.

\section{Governing equations}

The geometry of 2-lobe symmetric and asymmetric slot entry restrictor bearing system is shown in Figures 1a-1c. The differential equation governing the 
Prashant B. Kushare and Satish C. Sharma: Mechanics \& Industry 16, 502 (2015)

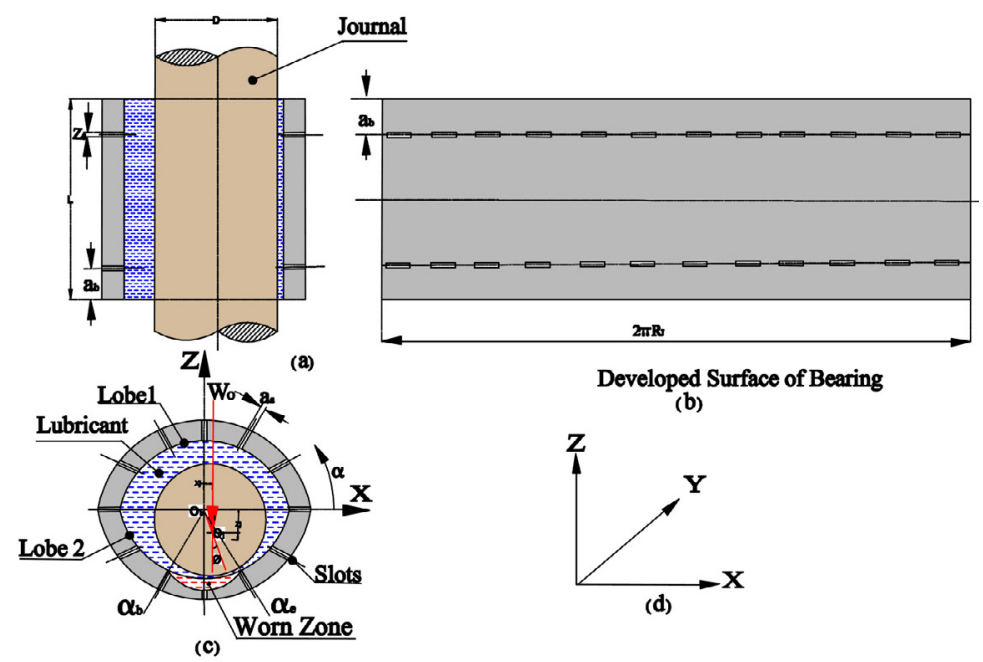

(a)

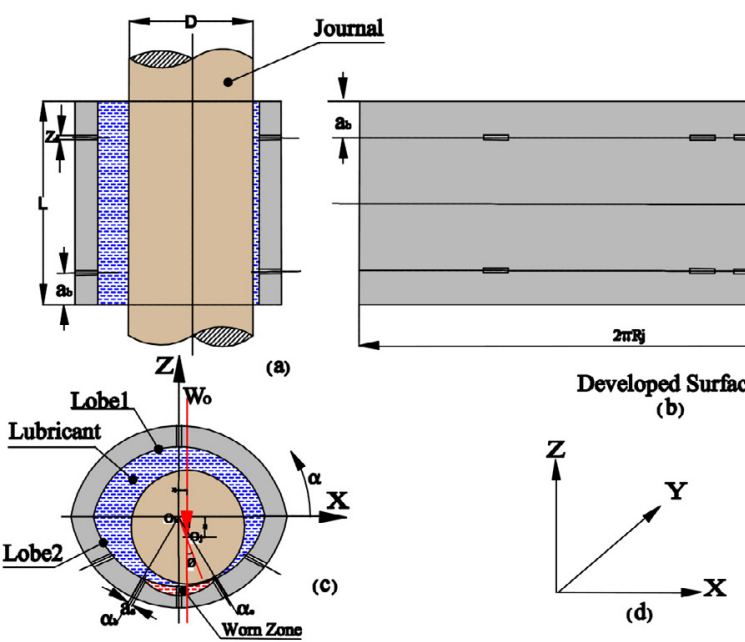

(b)

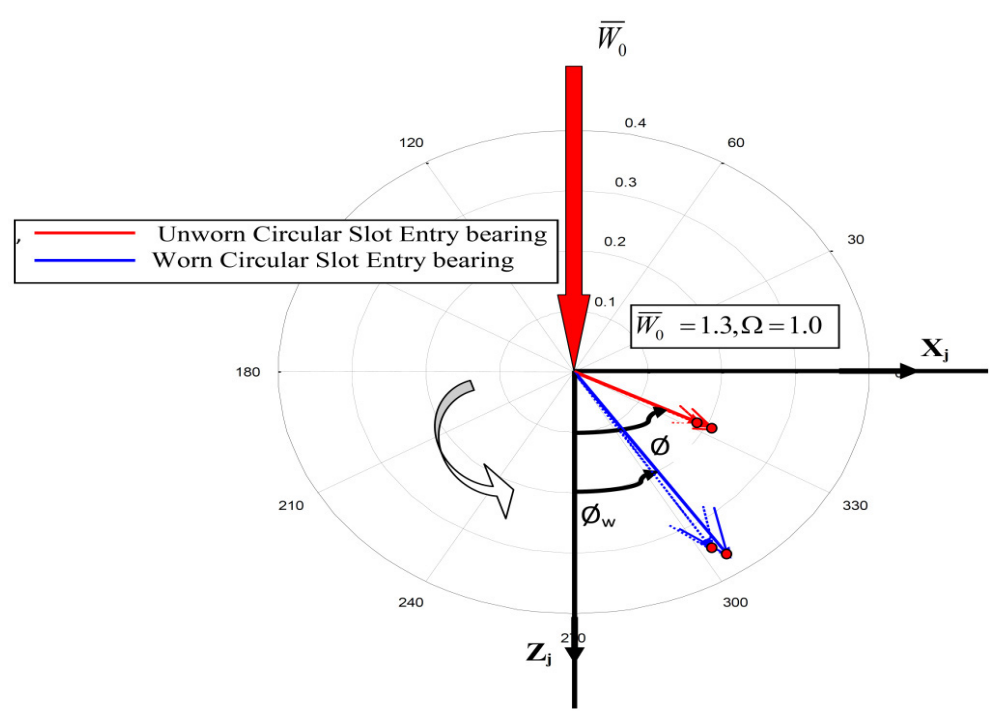

(c)

Fig. 1. (a) 2-lobe worn slot entry symmetric bearing configuration. (b) 2-lobe lobe worn slot entry asymmetric bearing configuration. (c) Attitude focus for worn and unworn symmetric bearing configuration. 
pressure distribution of incompressible laminar flow of lubricant is modified in the form of non-dimensional generalized Reynolds equation and is expressed as $[8,18,29,30]$ :

$$
\frac{\partial}{\partial \alpha}\left(\frac{\bar{h}^{3}}{6} \frac{\partial \bar{p}}{\partial \alpha}\right)+\frac{\partial}{\partial \beta}\left(\frac{\bar{h}^{3}}{6} \frac{\partial \bar{p}}{\partial \beta}\right)=\Omega\left[\frac{\partial \bar{h}}{\partial \alpha}\right]+2 \frac{\partial \bar{h}}{\partial \tau}
$$

\subsection{Fluid film thickness expression}

For a 2-lobe slot entry journal bearing system, the fluid-film thickness expression in non dimensional form is written as $[15,16,18]$

$$
\bar{h}_{L}=\frac{1}{\delta}-\left(\bar{X}_{j}+\bar{x}-\bar{X}_{L}^{i}\right) \cos \alpha-\left(\bar{Z}_{j}+\bar{z}-\bar{Z}_{L}^{i}\right) \sin \alpha
$$

where, $\bar{X}_{j}$ and $\bar{Z}_{j}$ are the equilibrium co-ordinates of the journal centre, $\bar{X}_{L}^{i}$ and $\bar{Z}_{L}^{i}$ are the lobe centre co-ordinates of $i$ th lobe. $\bar{x}$ and $\bar{z}$ are time dependent perturbation coordinates of the journal centre measured from its equilibrium position. The non-circularity of the bearing geometry is defined by offset factor $(\delta)$.

Using the footprint of worn out bearing surface identified by Dufrane et al. [22] the expression for the change in bearing surface geometry is written as $[18,22,24,25]$ :

$$
\partial \bar{h}=\bar{\delta}_{\mathrm{w}}-1-\sin \alpha \quad \text { for } \quad \alpha_{b} \leq \alpha \leq \alpha_{e}
$$

and

$$
\partial \bar{h}=0 \text { for } \alpha<\alpha_{b} \text { or } \alpha>\alpha_{e} \text { respectively }
$$

Thus, for worn 2-lobe slot entry journal bearing jounal bearing, the fluid-film thickness expression is written as:

$$
\bar{h}=\bar{h}_{L}+\partial \bar{h}
$$

\subsection{Slot entry restrictor flow equation}

The non dimensional flow of Newtonian lubricants through a slot entry restrictor is written as $[4,5,8]$ :

$$
\bar{Q}_{\text {in }}=\frac{1}{12 \eta}\left(\bar{p}_{c}-\bar{p}\right) \frac{a_{\mathrm{s}} Z_{\mathrm{s}}^{3}}{Y_{s}}
$$

The Equation (4) in non dimensional form is written as $[5,8]$ :

$$
\bar{Q}_{\mathrm{R}}=\bar{C}_{\mathrm{SR}}\left(1-\bar{p}_{c}\right)
$$

where, the parameter $\bar{C}_{\mathrm{SR}}$ is expressed as

$$
\bar{C}_{\mathrm{SR}}=\frac{\pi}{36} \frac{S W R}{\lambda} \frac{k}{\bar{a}_{b}} \frac{a_{b}}{Y_{\mathrm{s}}}\left[\frac{Z_{\mathrm{s}}}{c}\right]^{3}
$$

where Slot Width Ratio $(S W R)$ is defined as:

$$
S W R=\frac{a_{\mathrm{s}}}{\left(a_{\mathrm{s}}\right)_{\max }}=\frac{a_{\mathrm{s}} n}{\pi D}
$$

At the concentric operation of the bearing, the relation between concentric design pressure ratio $\bar{\beta}^{*}$ and slot restrictor design parameter $\bar{C}_{\mathrm{SR}}$ can be written as $[4,5,8]$ :

$$
\bar{C}_{\mathrm{SR}}=\frac{1}{k n} \frac{\pi}{6 \lambda \bar{a}_{b}}\left[\frac{\bar{\beta}^{*}}{1-\bar{\beta}^{*}}\right]
$$

\subsection{Finite element formulation}

The discretization of lubricant flow field of 2-lobe slot entry restrictor bearing has been made by using a 4-node isoparametric element. Using Galerkin's techniques, global system of equation is derived [13, 29, 30]:

$$
[\bar{F}]\{\bar{P}\}=\{\bar{Q}\}+\Omega\left\{\bar{R}_{H}\right\}+\overline{\dot{X}}_{J}\left\{\bar{R}_{x j}\right\}+\overline{\dot{Z}}_{J}\left\{\bar{R}_{z j}\right\}
$$

At a point in the fluid film, the total pressure $(\bar{p})$ may be expressed as sum of the steady state pressure $\left(\bar{p}_{0}\right)$ and pressures $\left(\bar{p}_{X_{j}}, \bar{p}_{Z_{j}}\right)$ caused by journal centre velocities $\left(\overline{\dot{X}}_{j}, \overline{\dot{Z}}_{j}\right)$. Subsequently, the nodal pressure matrix may be written as $\{\bar{p}\}=\left\{\bar{p}_{0}\right\}+\left\{\bar{p}_{X j}\right\}+\left\{\bar{p}_{Z_{j}}\right\}$. The solution of equations [9], satisfying all the boundary conditions and continuity of flow between the restrictor and bearing provides the nodal pressures and bearing flows. Knowing the nodal pressures and bearing flows, the steady state performance in terms of load capacity, slot pressures and total bearing flow can be computed. Establishing the steady state matched solution of global system equation and slot entry restrictor equation, the fluid film stiffness and damping coefficients are computed using the derivatives of nodal pressures w.r.t $\left(\bar{X}_{j}, \bar{Z}_{j}\right)$ and $\left(\overline{\dot{X}}_{j}, \overline{\dot{Z}}_{j}\right)$ respectively.

\subsection{Dynamic performance characteristics}

The rotor dynamic coefficients are computed using the following expressions as reported in References $[8,9,13,17$, $18,20]$.

\subsubsection{Fluid-film stiffness coefficients}

$$
\bar{S}_{i j}=-\frac{\partial \bar{F}_{i}}{\partial q}(i=x, z)
$$

Stiffness coefficient in matrix form may be written as:

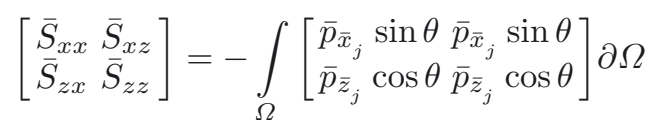

\subsubsection{Fluid-film damping coefficients}

$$
\bar{C}_{i j}=-\frac{\partial \bar{F}_{i}}{\partial \dot{q}}(i=x, z)
$$

In matrix form, damping coefficients may be expressed as:

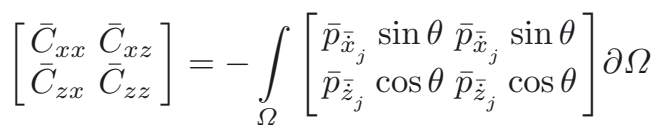




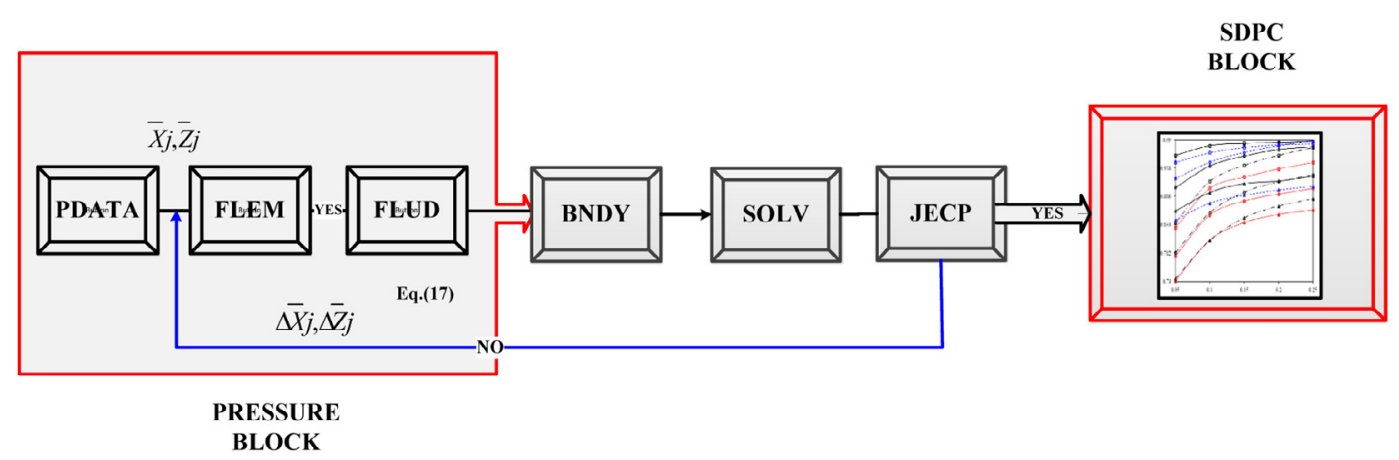

Fig. 2. Overall solution scheme.

\subsubsection{Stability parameters}

Using Rouths' criteria, the stability parameter; a critical mass of the journal $\left(\bar{M}_{c}\right)$ is written as $[13,21]$ :

$$
\bar{M}_{c}=\frac{\bar{G}_{1}}{\bar{G}_{2}-\bar{G}_{3}}
$$

where,

$$
\begin{aligned}
\bar{G}_{1} & =\left[\bar{C}_{x x} \bar{C}_{z z}-\bar{C}_{z x} \bar{C}_{x z}\right] \\
\bar{G}_{2} & =\frac{\left[\bar{S}_{x x} \bar{S}_{z z}-\bar{S}_{z x} \bar{S}_{x z}\right]\left[\bar{C}_{x x}+\bar{C}_{z z}\right]}{\left[\bar{S}_{x x} \bar{C}_{z z}+\bar{S}_{z z} \bar{C}_{x x}-\bar{S}_{x z} \bar{C}_{z x}-\bar{S}_{z x} \bar{C}_{x z}\right]} \\
\bar{G}_{3} & =\frac{\left[\bar{S}_{x x} \bar{C}_{x x}+\bar{S}_{x z} \bar{C}_{x z}+\bar{S}_{z x} \bar{C}_{z x}+\bar{S}_{z z} \bar{C}_{z z}\right]}{\left[\bar{C}_{x x}+\bar{C}_{z z}\right]}
\end{aligned}
$$

Stability threshold speed margin is written as:

$$
\bar{\omega}_{\mathrm{th}}=\left[\bar{M}_{c} / \bar{F}_{0}\right]^{1 / 2}
$$

\subsection{Boundary conditions}

The differential equations governing the pressure distribution and restrictor flow equation are solved simultaneously by using the following associated pressure boundary conditions $[13,18,29]$ :

(a) The nodes situated at the external boundary of the bearing have zero fluid film pressure. $\left.\bar{p}\right|_{\beta=\mp 1.0}=0.0$.

(b) Nodes situated on slot have equal value of fluid film pressure.

(c) At the trailing edge of the positive region, $\bar{p}=\frac{\partial \bar{p}}{\partial \alpha}=$ 0.0 ; Reynolds boundary condition.

\section{Solution procedure}

To constitute the solution of the flow field system equation, the fluid flow field system equation [9] that governs the flow of 2-lobe slot entry restrictor bearing is solved by an iterative solution scheme. The procedure of an iterative scheme used to get the required convergence of the solution has been presented in Figure 2 . The FEM solution of the lubricant flow field of a bearing has been obtained by discretizing it with quadrilateral isoparametric elements. The initial trial solution is carried out for a Newtonian lubricant and steady state condition, $\overline{\dot{X}}_{j}=0.0$ and $\overline{\dot{Z}}_{j}=0.0$, the values of fluid film thickness at all the nodal points are calculated in unit FLEM by using Equation (3). Using generated fluidity matrices, the system equations are solved to get nodal values of pressure. The iterative process continues until the required convergence of difference in nodal pressures at each node becomes less than the predefined tolerance. It is achieved in PRESSURE block through the up gradation of the solution. The modified fluidity system equation is generated by using BNDY unit. The journal center equilibrium is established through an iterative technique in unit JECP. The iterative process is continued until the required difference in journal center coordinates falls below the required tolerance. i.e.

$$
\left[\frac{\left\{\left(\Delta \bar{X}_{j}^{i}\right)^{2}+\left(\Delta \bar{Z}_{j}^{i}\right)^{2}\right\}^{1 / 2}}{\left\{\left(\bar{X}_{j}^{i}\right)^{2}+\left(\bar{Z}_{j}^{i}\right)^{2}\right\}^{1 / 2}}\right] \times 100 \leq 0.001 .
$$

After achieving equilibrium in JECP, the above obtained nodal pressure is used as the input variable to compute the performance of the bearing system in SDPC block.

\section{Results and discussion}

The performance characteristics of a 2-lobe slot entry restrictor bearing configuration has been computed by employing the developed numeric model and overall solution scheme as described in previous sections. As stated earlier, there are no results available in the published literature for the case of worn 2-lobe slot entry restrictor bearing. Therefore, the results of the present study have been compared and validated using the published results 


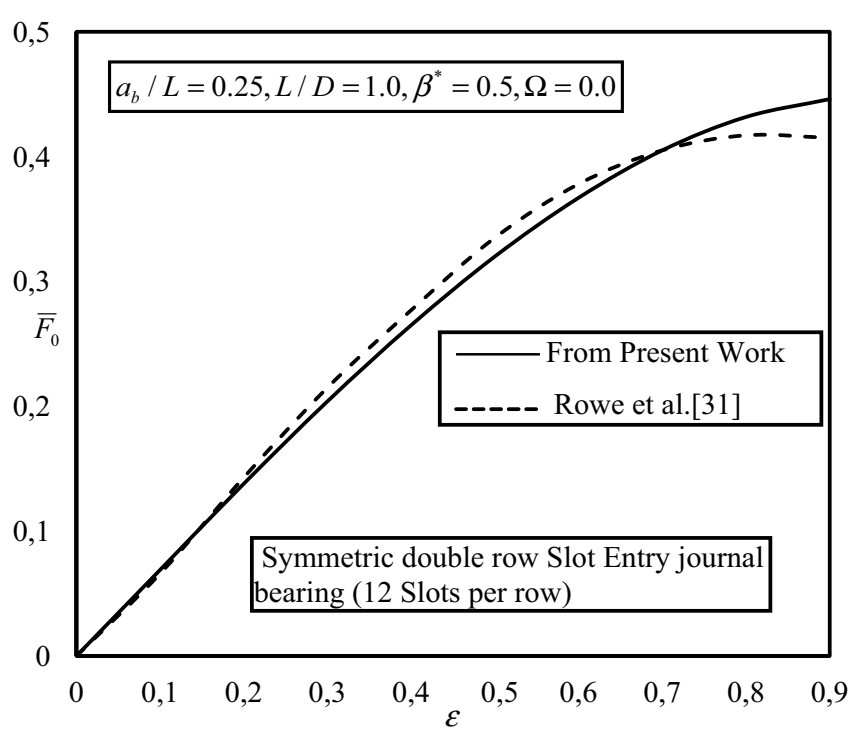

Fig. 3. Fluid film reaction $\left(\bar{F}_{0}\right)$ with an eccentricity ratio $(\varepsilon)$.

of Rowe et al. [31] and Hashimoto et al. [23] for the case of slot entry restrictor bearing and wear study of hydrodynamic journal bearing respectively. For circular slot entry restrictor bearing system, the computed results are validated with the published results of Rowe et al. [31] and are shown in Figure 3. The numerically simulated results from the present study are quite close to those of Rowe et al. [31]. Further, the computed results have also been validated with the published results of Hashimoto, et al. [23] for worn $\left(\bar{\delta}_{\mathrm{w}}=0.4\right)$ and unworn $\left(\bar{\delta}_{\mathrm{w}}=0.0\right)$ hydrodynamic plain journal bearing as shown in Figure 4. The results of the present study match very well with the results of Hashimoto et al. [23] with a minor deviation of $2 \%-4 \%$. This deviation in results may be attributed due to the different computational schemes used in the studies. The bearing performance characteristics of a 2lobe slot entry restrictor hybrid journal bearing have been computed by using the judiciously selected bearing parameters. The bearing parameters have been selected on the basis of their wide applications and are taken from already published literature $[4,5,8,15,16,18,22-24,31]$. The values of bearing parameters are shown in Table 1 . The static and dynamic performance characteristics of 2-lobe slot entry bearing have been computed for the different values of wear depth parameter $\left(\bar{\delta}_{\mathrm{w}}=0.0,0.5\right)$ and offset factor $(\delta=1.1,1.0$ and 0.9$)$. The defects caused by wear are found to be ranged from $10 \%$ to $50 \%$ of the bearing radial clearance $[18,19,22]$. The wear defect more than $30 \%$ of the bearing radial clearance significantly affects the bearing performance $[18,22]$. Therefore, in numerical analysis, the value of $\bar{\delta}_{\mathrm{w}}=0.5$ is considered to represent the worn bearing and $\bar{\delta}_{\mathrm{w}}=0.0$ for the unworn bearing. For the sake of brevity, the results are presented for attitude angle $(\varphi)$, Fluid-film Pressure $(\bar{p})$ distribution at axial mid plane, fluid film thickness distribution at axial midplane $(\bar{h}), \bar{h}_{\text {min }}, \bar{\omega}_{\text {th }}, \bar{S}_{22}$ and $\bar{C}_{22}$ through Figures $5-$ 11 for both 2-lobe slot entry symmetric and asymmetric bearing respectively.

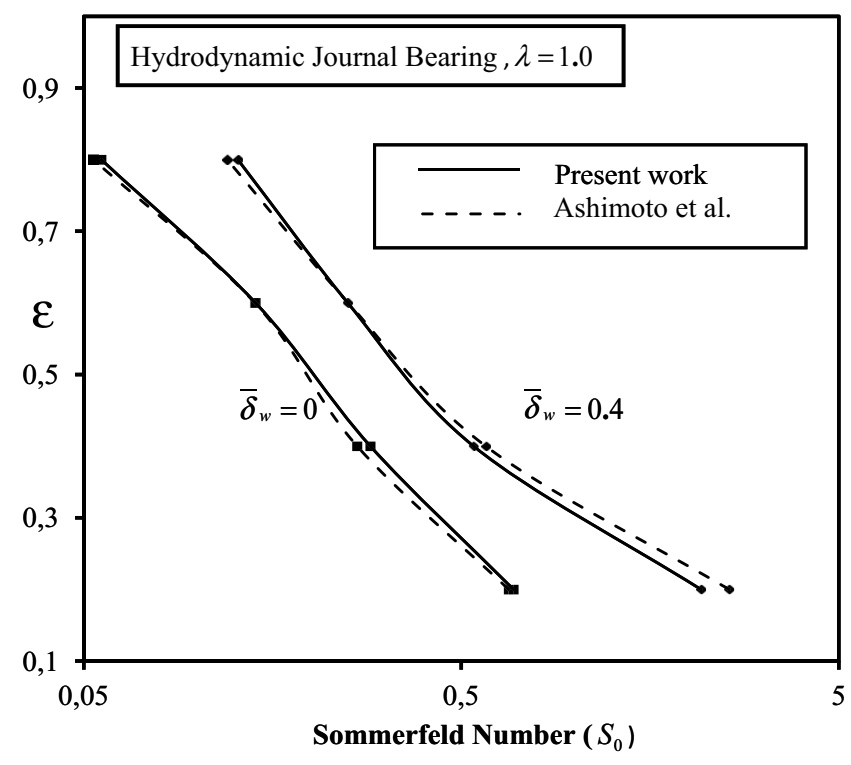

Fig. 4. Variation of Eccentricity ratio $(\varepsilon)$ with Sommerfeld number $\left(S_{0}\right)$.

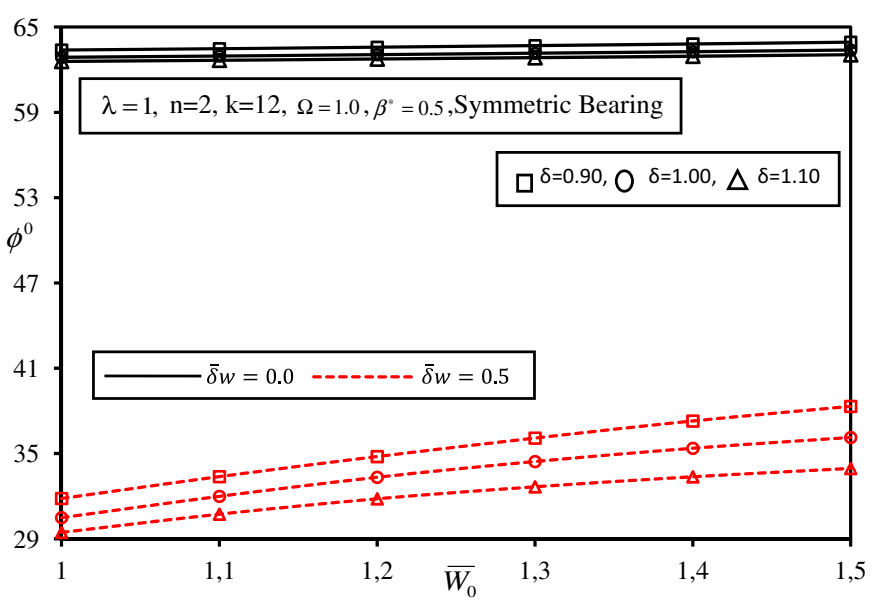

(a)

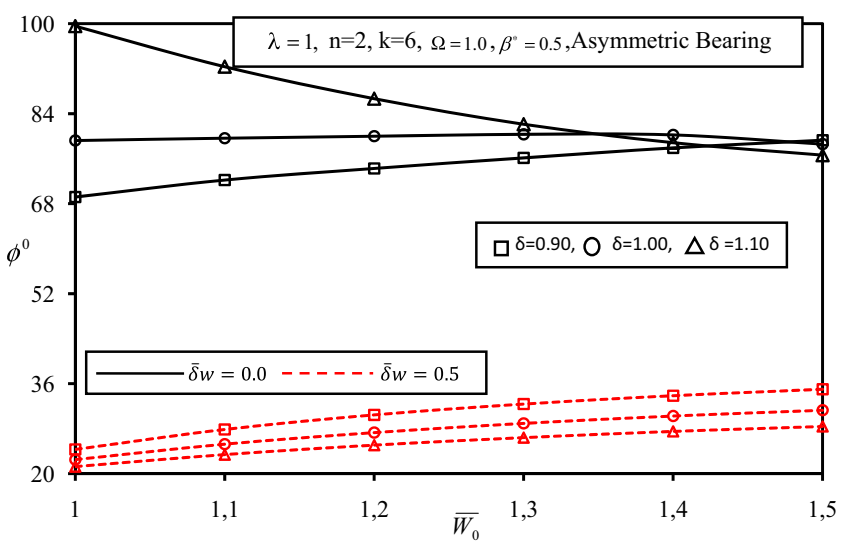

(b)

Fig. 5. (a) Attitude angle $(\varphi)$ for symmetric slot entry bearing. (b) Attitude angle $(\varphi)$ for asymmetric slot entry bearing. 
Prashant B. Kushare and Satish C. Sharma: Mechanics \& Industry 16, 502 (2015)

Table 1. Bearing Parameters for 2- lobe slot entry hybrid journal bearing.

\begin{tabular}{|c|c|c|c|}
\hline \multicolumn{2}{|c|}{ Operating parameters } & \multicolumn{2}{|c|}{ Geometric parameters } \\
\hline Parameters & Value/ Range & Parameters & Value \\
\hline External Load $\left(W_{0}\right)$ & $0.5-0.9$ & Aspect Ratio $(\lambda)$ & 1.0 \\
\hline \multirow{2}{*}{\multicolumn{2}{|c|}{ Symmetric bearing configuration }} & No. of slots per row $(\mathrm{k})$ & 12 \\
\hline & & No. of rows $(\mathrm{n})$ & 02 \\
\hline \multirow{2}{*}{\multicolumn{2}{|c|}{ Asymmetric bearing configuration }} & No. of slots per row $(\mathrm{k})$ & 06 \\
\hline & & No. of rows $(\mathrm{n})$ & 02 \\
\hline Restrictor flow parameter $\left(C_{S R}\right)$ & 0.087 & \multirow{2}{*}{ Land width ratio $\left(\bar{a}_{b}\right)$} & \multirow{2}{*}{0.25} \\
\hline Speed $(\Omega)$ & 1.0 & & \\
\hline $\begin{array}{l}\text { Wear depth parameter }\left(\delta_{\mathrm{w}}\right) \\
\text { Offset factor }(\delta)\end{array}$ & $\begin{array}{c}0.0 \text { and } 0.5 \\
0.9,1.0 \text { and } 1.1\end{array}$ & Clearance ratio $(\bar{c})$ & 0.001 \\
\hline
\end{tabular}

\subsection{Attitude angle $(\varphi)$}

Figures $5 \mathrm{a}$ and $5 \mathrm{~b}$ show variation of attitude angle of symmetric and asymmetric journal bearings configurations respectively. It is observed that with an increase in external load $\bar{W}_{o}$, the journal center goes down for both the configurations thereby increasing the eccentricity ratio $(\varepsilon)$. Thus, the worn bearing operates at high eccentricity ratio and lower value of attitude angle in case of both configurations. At a specified value of external load, in worn journal bearing, offset factor greater than one decreases the value of attitude angle $(\varphi)$ for both configurations. This behavior is similar to the pattern reported in experimental study of Fillon and Bouyer [25]. For symmetric configuration it is noted that attitude angle remains nearly same with increase in the external load for the case of unworn journal bearings for all the values of offset factor whereas, this trend has been changed in unworn asymmetric bearing configuration.

\subsection{Fluid-film pressure $(\bar{p})$ distributions}

Figures $6 \mathrm{a}$ and $6 \mathrm{~b}$ depict the circumferential fluid-film pressure distribution for symmetric and asymmetric bearing configurations at the axial midplane respectively. It may be observed that fluid film pressure is maximum nearly at about $\alpha=3 \times 10^{\circ}$ for worn journal bearing i.e. in the direction of external load for both the symmetric as well as asymmetric bearing configuration. This is attributed because of an increased convergent zone at the bottom of worn bearing surface. It is further observed that symmetric bearing operates at higher value of pressure than that of asymmetric bearing configuration. Further, for unworn case the value of circumferential pressures is less than that of worn bearing. This behavior is consistent with the earlier results of References [25,32]. Further, it may be observed that the lobed bearing at offset factor greater than one provides a higher value of pressure than that of a circular journal bearing. The worn out bearing surface creates two converging and one diverging zone. As a consequence of this, in the divergent zone of wear defect, pressure gets reduced after one peak and later on further increases at the end of the wear zones.

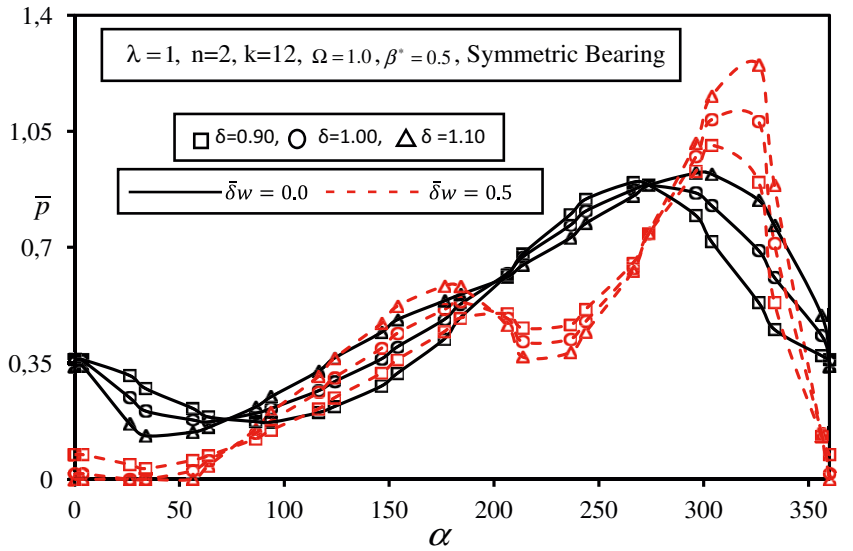

(a)

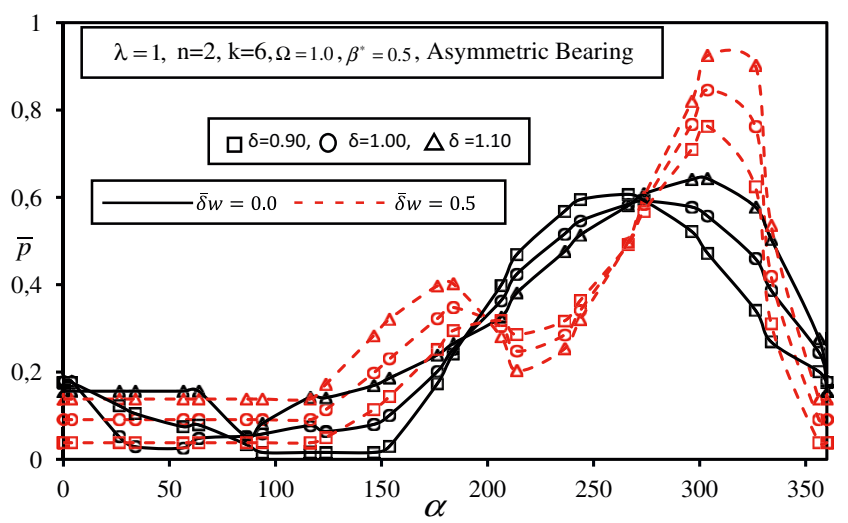

(b)

Fig. 6. (a) Circumferential pressure distribution for symmetric slot entry bearing. (b) Circumferential pressure distribution for asymmetric slot entry bearing.

\subsection{Minimum fluid film thickness $\left(\bar{h}_{\text {min }}\right)$}

Figures $7 \mathrm{a}$ and $7 \mathrm{~b}$ show the variation of minimum fluid-film thickness $\left(\bar{h}_{\text {min }}\right)$ for 2-lobe slot entry symmetric and asymmetric bearing configurations respectively. It is observed from the curves of Figure $7 \mathrm{a}$ that for a given value of an external load $\left(\bar{W}_{0}\right)$, the value of $\bar{h}_{\text {min }}$ gets reduced for symmetric slot entry bearing configuration. For 


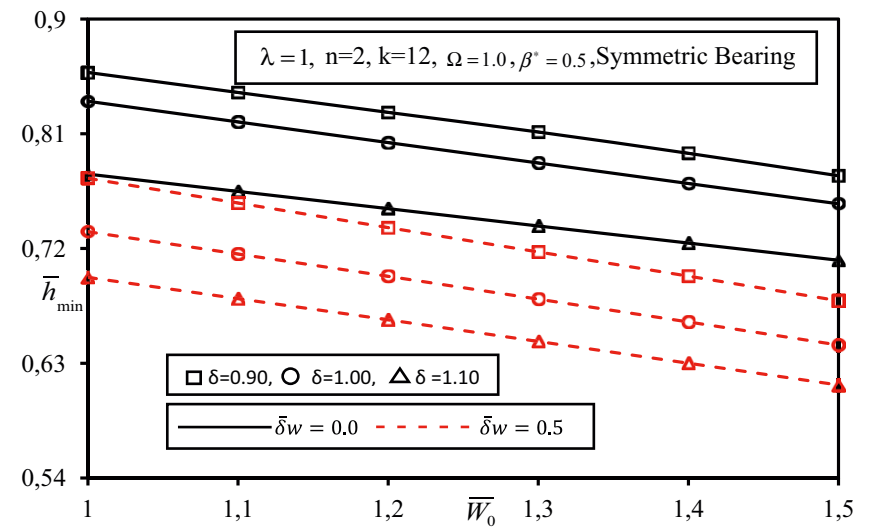

(a)

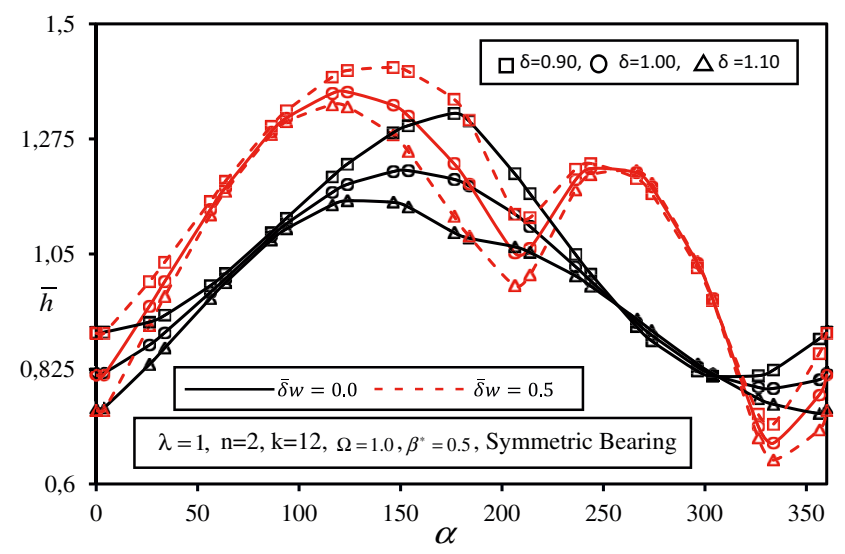

(c)

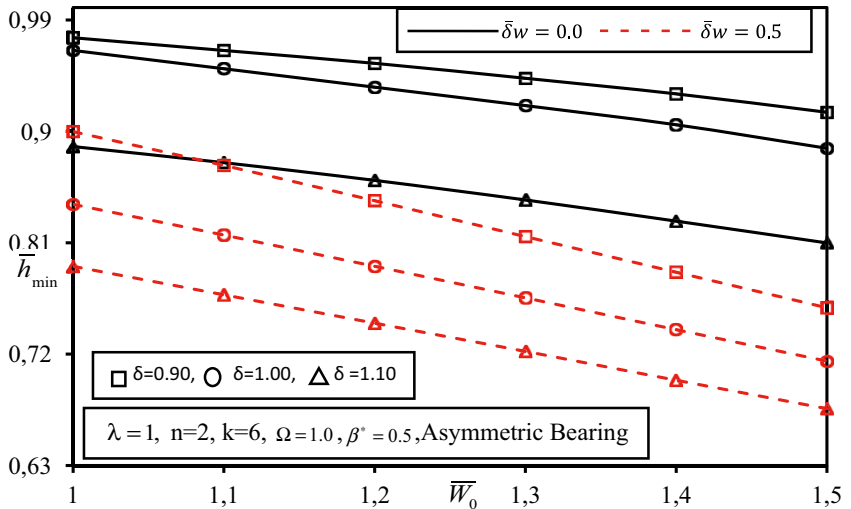

(b)

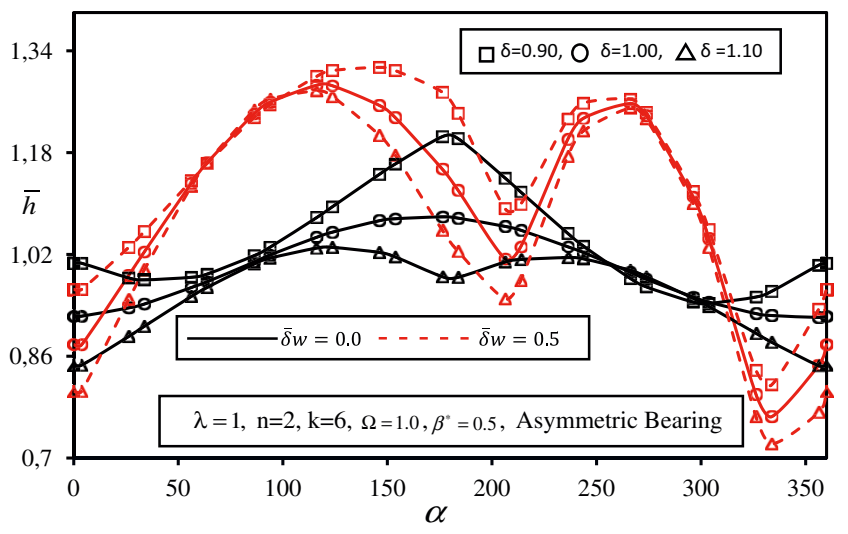

(d)

Fig. 7. (a) Minimum fluid film thickness $\left(\bar{h}_{\text {min }}\right)$ for symmetric slot entry bearing. (b) Minimum fluid film thickness $\left(\bar{h}_{\text {min }}\right)$ for asymmetric slot entry bearing. (c) Fluid film thickness distribution $(\bar{h})$ for symmetric slot entry bearing. (d) Fluid film thickness distribution $(\bar{h})$ for asymmetric slot entry bearing.

symmetric slot entry restrictor configuration, it may be noted that when influence of wear defect is taken into account, the value of $\bar{h}_{\text {min }}$ decreases substantially and bearing operates at a lower value $\bar{h}_{\text {min }}$. It is also observed that at lower values of external load, the value of $\bar{h}_{\text {min }}$ is higher for worn and unworn symmetric slot entry restrictor bearing. At the value of $\delta=1.1$ and $\bar{\delta}_{\mathrm{w}}=0.5$; symmetric slot entry bearing configuration has a lower value of $\bar{h}_{\text {min }}$. The reduction in the value of $\bar{h}_{\text {min }}$ for asymmetric configuration is quite significant for worn out bearing as shown in Figure 7b. The value of $\bar{h}_{\text {min }}$ gets decreased considerably at the higher values of external loads $\left(\bar{W}_{o}=1.2,1.3\right)$ for worn out bearing surface. The value of $\bar{h}_{\text {min }}$ decreases when the value of external load $\bar{W}_{0}$ acting on bearing increases for asymmetric 2-lobe slot entry bearing configuration when compared with that of symmetric bearing configuration. For asymmetric bearing configuration, the value of $\bar{h}_{\text {min }}$ is observed to be higher for higher values of external load $\left(\bar{W}_{0}\right)$. This is due to the higher load carrying capacity of the asymmetric 2-lobe slot entry bearing at lower values of eccentricity ratio. Further, at the value of offset factor $(\delta=0.9)$, 2-lobe slot entry bearing runs at higher values of $\bar{h}_{\text {min }}$ for both the bearing configurations.
Figure 11a depicts the bar chart of percentage change in the value of minimum fluid film thickness $\left(\bar{h}_{\text {min }}\right)$ with respect to the base bearing for the case of 2-lobe symmetric and asymmetric slot entry bearing configurations respectively. The maximum reduction in the value of $\bar{h}_{\min }$ is observed to be about $17.78 \%$ for worn $\left(\bar{\delta}_{w}=0.5\right)$ noncircular bearing configuration $(\delta=1.1)$. This is due to large clearance at worn zone of the bearing surface. As a consequence of this, journal tends to go down towards the worn out zone of the bearing surface. This increases the eccentricity ratio and bearing runs at lower values of $\bar{h}_{\text {min }}$. For the same operating condition, the maximum reduction in the value of $\bar{h}_{\text {min }}$ is observed to the order of $6.27 \%$ for unworn journal bearing. For asymmetric bearing configuration, the maximum decrease in the value of $\bar{h}_{\text {min }}$ is observed to be of the order of $8.27 \%$ for $\bar{\delta}_{w}=0.0$ when compared with circular unworn bearing. The worn out bearing surface defined by wear defect parameter $\left(\bar{\delta}_{w}\right)$ has a more significant effect on symmetric bearing configuration than for the asymmetric bearing configuration. Thus, to avoid the failure of bearing and to maintain the optimum range of minimum value of fluid film thickness $\left(\bar{h}_{\text {min }}\right)$; a proper care must be taken by bearing designer 


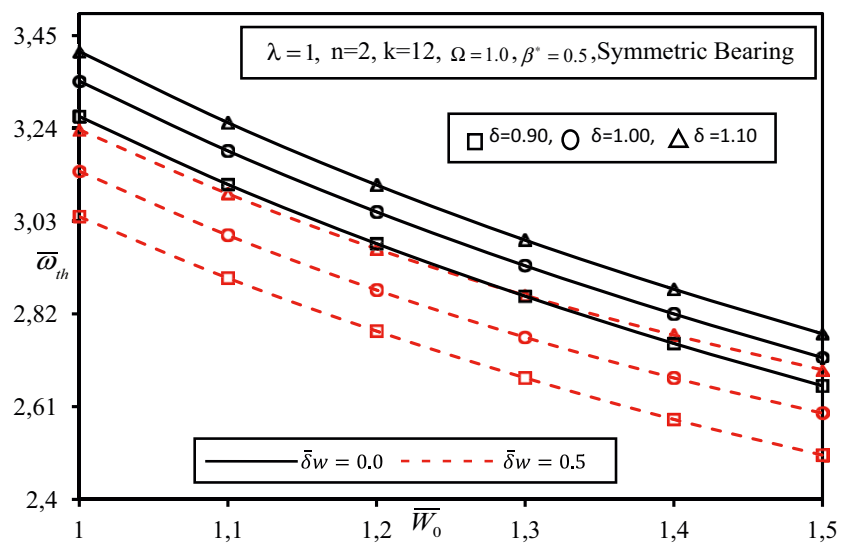

(a)

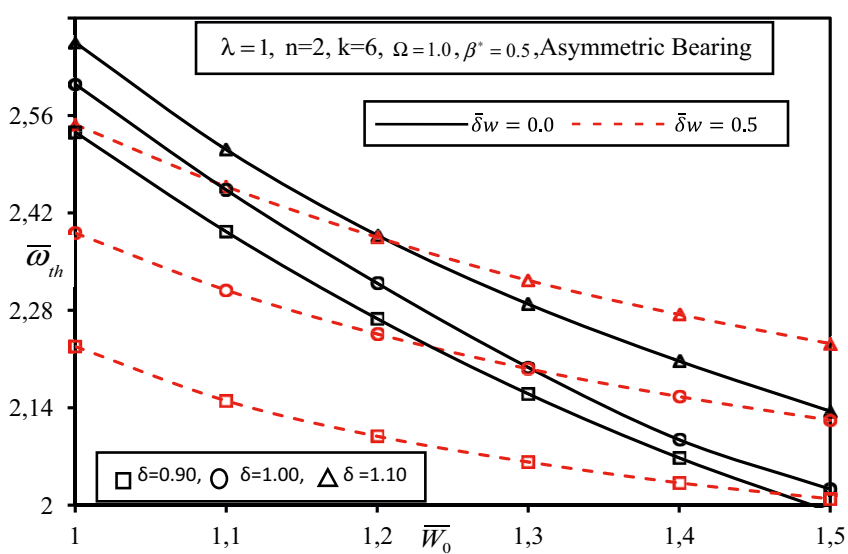

(b)

Fig. 8. (a) Threshold speed margin $\bar{\omega}_{\text {th }}$ for symmetric slot entry bearing. (b) Threshold speed margin $\bar{\omega}_{\text {th }}$ for asymmetric slot entry bearing.

during the selection of geometric and operating parameters.

\subsection{Fluid film thickness distribution $(\bar{h})$}

For a specified value of external load $\bar{W}_{0}=1.2$, the distribution of fluid film thickness along axial midplane is presented for a symmetric and asymmetric 2-lobe slot entry hybrid journal bearing system are presented in Figures $7 \mathrm{c}$ and $7 \mathrm{~d}$ respectively. It may be clearly observed that the wear defect significantly affects value of fluid film thickness. Further, the value of fluid film thickness is reduced for bearing with offset factor $\delta>1.0$ when compared with circular journal bearing system. At the starting and end of the worn region, formation of converging zone decreases the values of fluid film thickness and creats the two zones in film thickness profile in both the configurations. The nature of fluid film thickness profile depicted in Figures $7 \mathrm{c}$ and $7 \mathrm{~d}$ is similar to the work of Fillon and Bouyer [25], their study reported the reduced value of fluid film thickness at midplane for hydrodynamic

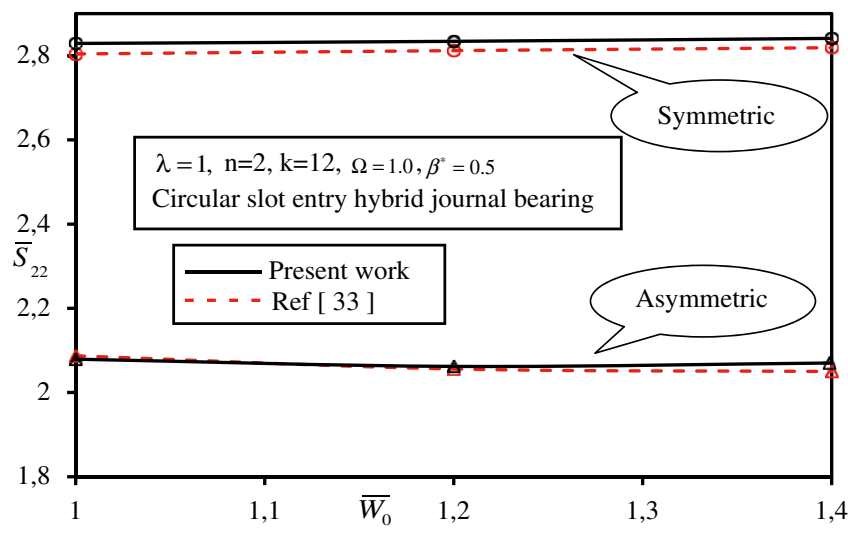

(a)

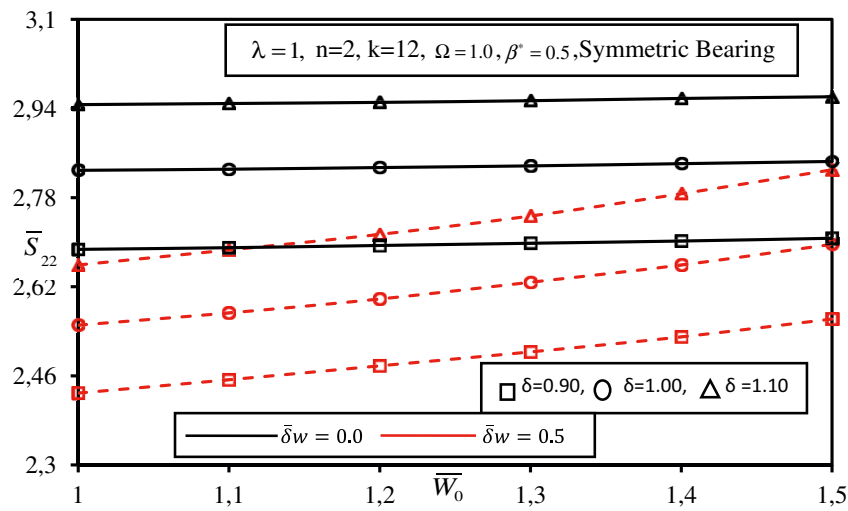

(b)

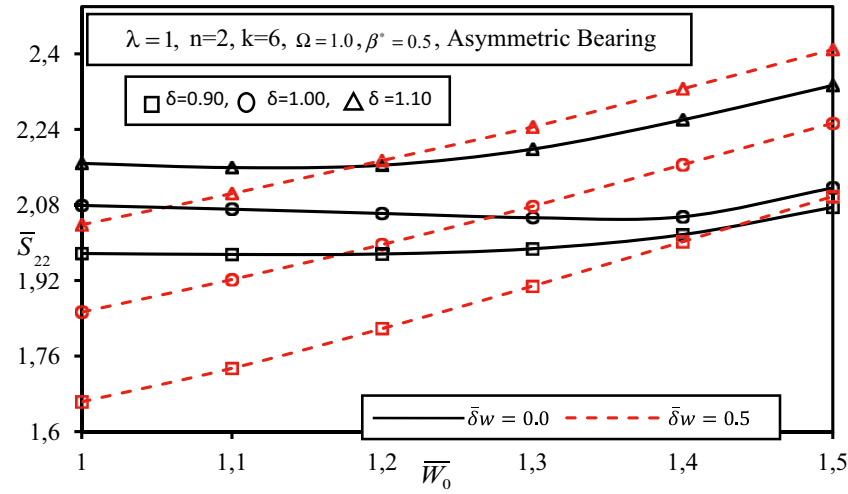

(c)

Fig. 9. (a) Direct fluid film stiffness coefficient $\left(\bar{S}_{22}\right)$ for symmetric and asymmetric circular slot entry bearing. (b) Direct fluid film stiffness coefficient $\left(\bar{S}_{22}\right)$ for symmetric slot entry bearing. (c) Direct fluid film stiffness coefficient $\left(\bar{S}_{22}\right)$ for asymmetric slot entry bearing.

journal bearing with an increase in wear defect except for the case of low speed and high load.

\subsection{Stability threshold speed margin $\left(\bar{\omega}_{t h}\right)$}

The variation of stability threshold speed margin $\left(\bar{\omega}_{\mathrm{th}}\right)$ is shown in Figures $8 \mathrm{a}$ and $8 \mathrm{~b}$. The value of $\bar{\omega}_{t h}$ gets 
decreased with an increase in the value of $\bar{\delta}_{w}$. Further, it may be noticed that the wear defect has a subsidiary effect on the value of $\bar{\omega}_{\text {th }}$ for symmetric bearing configuration than for the asymmetric bearing configuration. The dynamic response of worn $\left(\bar{\delta}_{w}=0.5\right)$ bearing is observed to decrease the value of stability threshold speed margin $\left(\bar{\omega}_{t h}\right)$ substantially in case of asymmetric 2-lobe slot entry restrictor bearing configuration.

The symmetric 2-lobe slot entry bearing operating at the value of offset factor $\delta=0.9$ is observed to provide the lowest value of stability threshold speed margin $\left(\bar{\omega}_{\text {th }}\right)$. Further; for a specified value of $\bar{W}_{0}=1.3$ and $\bar{\delta}_{w}=0.5$ it is observed that 2-lobe slot entry journal bearing $(\delta=1.1)$ provides higher value of threshold speed margin than that of circular journal bearing $(\delta=1.0)$. The percentage change in the value of $\bar{\omega}_{\text {th }}$ is presented in Figure 11b for both symmetric and asymmetric 2-lobe slot entry restrictor bearing configuration. The worn out bearing shows deterioration in the value of stability threshold speed margin $\left(\bar{\omega}_{\text {th }}\right)$ and confers the maximum reduction of $8.67 \%$ and $6.18 \%$ at $\delta=0.9$ for both symmetric and asymmetric configurations respectively. This is attributed to the changes in fluid film dynamic coefficients. The threshold speed margin is a function of dynamic coefficients and the same behavior of increase or decrease in the value of $\bar{\omega}_{\text {th }}$ is observed. The unworn 2-lobe symmetric slot entry journal bearing $(\delta>1.1)$ has a larger value of $\bar{\omega}_{\text {th }}$ than that of worn and unworn journal bearing. However, the 2-lobe worn asymmetric slot entry bearing configuration provides highest value of $\bar{\omega}_{\text {th }}$ for the same operating parameters. This is due to the high value of external load and large quantity of lubricant flow accumulated in the worn out zone of bearing. The maximum enhancement in the value of stability threshold speed margin $\left(\bar{\omega}_{\text {th }}\right)$, due to $\delta=1.1$ and $\bar{\delta}_{\mathrm{w}}=0.0$ is found to be of the order of $1.98 \%$ and $5.68 \%$ for both symmetric and asymmetric bearings respectively. Further, the results presented in Figure $11 \mathrm{~b}$, reveals that a proper choice of bearing geometry and bearing configuration is essential for obtaining a particular value of $\bar{\omega}_{\text {th }}$.

\subsection{Direct fluid-film stiffness coefficients $\left(\bar{S}_{22}\right)$}

The comparative study of direct fluid film stiffness coefficient $\left(\bar{S}_{22}\right)$ with the respect to the available results of earlier published study [33] of a slot entry circular journal bearings has been presented in Figure 9a. The results of the present study for symmetric and asymmetric bearing configuration match very well with the published study of Vijaykumar et al. [33]. The variation in the direct fluid film stiffness coefficient $\left(\bar{S}_{22}\right)$ with external load for symmetric and asymmetric 2-lobe slot entry journal bearings is shown in Figures 9a and 9b. It may be noted that the value of direct fluid film stiffness coefficient $\left(\bar{S}_{22}\right)$ gets decreased for the value of wear defect $\left(\bar{\delta}_{\mathrm{w}}=0.5\right)$ for symmetric 2 -lobe slot entry restrictor bearing. The presence of wear defect $\left(\bar{\delta}_{w}\right)$ has a substantial influence on the value of $\bar{S}_{22}$. The worn symmetric 2-lobe slot entry bearing configuration provides a lower value of $\bar{S}_{22}$ when

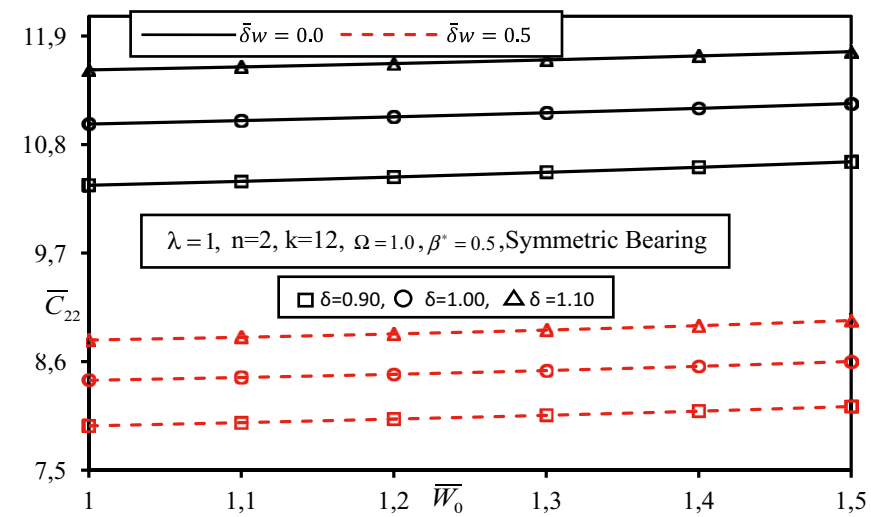

(a)

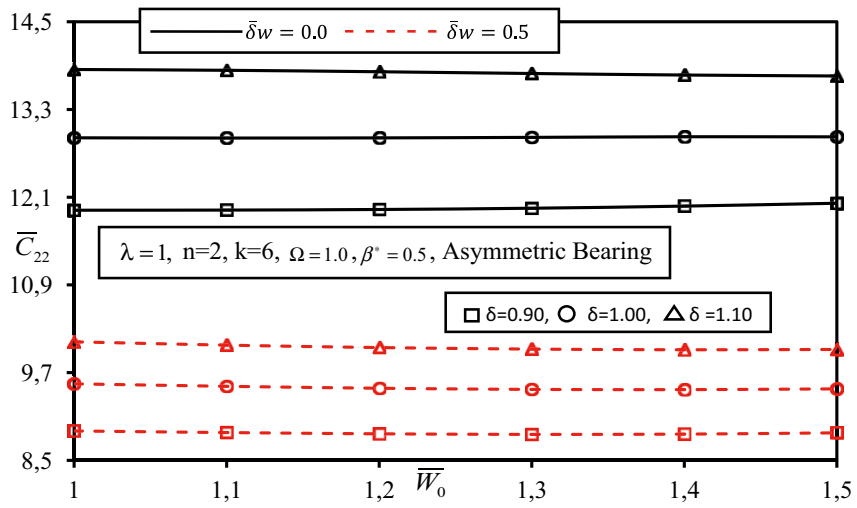

(b)

Fig. 10. (a) Direct fluid film damping coefficient $\left(\bar{C}_{22}\right)$ for symmetric slot entry bearing. (b) Direct fluid film damping coefficient $\left(\bar{C}_{22}\right)$ for asymmetric slot entry bearing.

it operates at $\delta=0.90$. Further, it has also been divulged that the non-circular bearing at the value of $\delta=1.1$, offers a higher value of $\bar{S}_{22}$ than that of the circular journal bearing $(\delta=1.0)$. Figure $9 \mathrm{~b}$ indicates that the effect of increase of $\bar{\delta}_{\mathrm{w}}$ is to trim down the value of $\bar{S}_{22}$. At higher value of external load $\left(\bar{W}_{0} \geq 1.3\right)$, the value of $\bar{S}_{22}$ gets increased for asymmetric noncircular $(\delta>1.0)$ and circular bearing configuration for $\bar{\delta}_{\mathrm{w}}=0.5$. However, an opposite trend is found in the value of $\bar{S}_{22}$ for unworn asymmetric bearing configuration. The percentage change in the value of $\bar{S}_{22}$ for both the 2-lobe slot entry configurations is presented in Figure 11c. When bearing operates at $\bar{\delta}_{\mathrm{w}}=0.5$, the values of $\bar{S}_{22}$ for symmetric 2-lobe slot entry bearing show a decreasing trend and are observed to offer a lower value than that of asymmetric bearing configuration. In case of asymmetric 2-lobe slot entry bearing configuration, the wear depth parameter $\bar{\delta}_{w}=0.5$ shows higher influence on the value of $\bar{S}_{22}$ at the lower value of external load $\left(\bar{W}_{0} \leq 1.3\right)$. The reduction in the value of $\bar{S}_{22}$ for wear defect of $50 \%$ of the radial clearance in case of symmetric bearing is found to be of the order of $317 \%, 736 \%$ and $1177 \%$ at the value of offset factor $\delta=1.1,1.0$ and 0.9 respectively. Further it is observed that an increase in the value of the offset factor $(\delta \geq 1.0)$; compensates the 


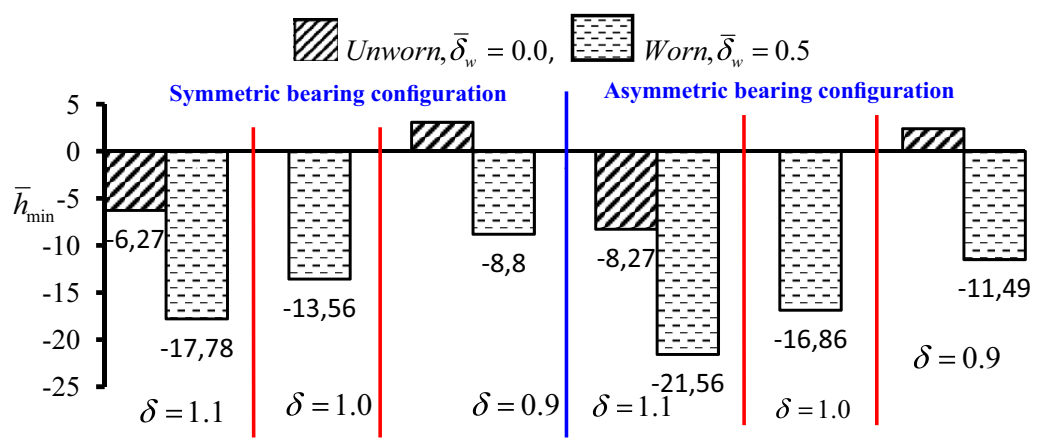

(a)

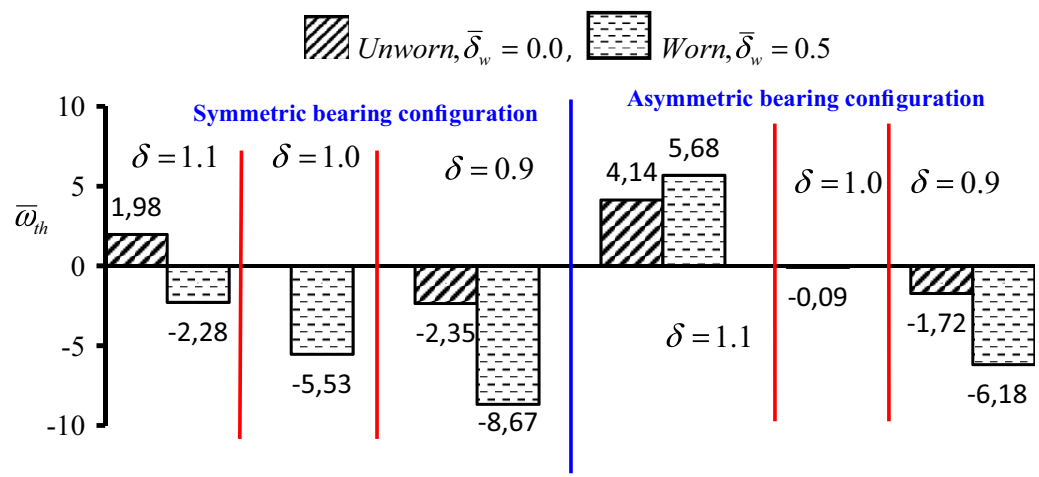

(b)

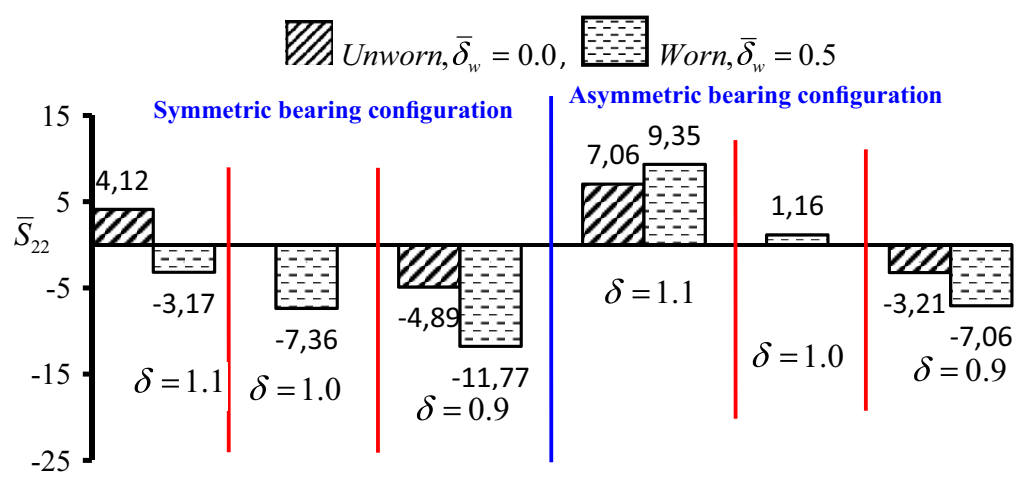

(c)

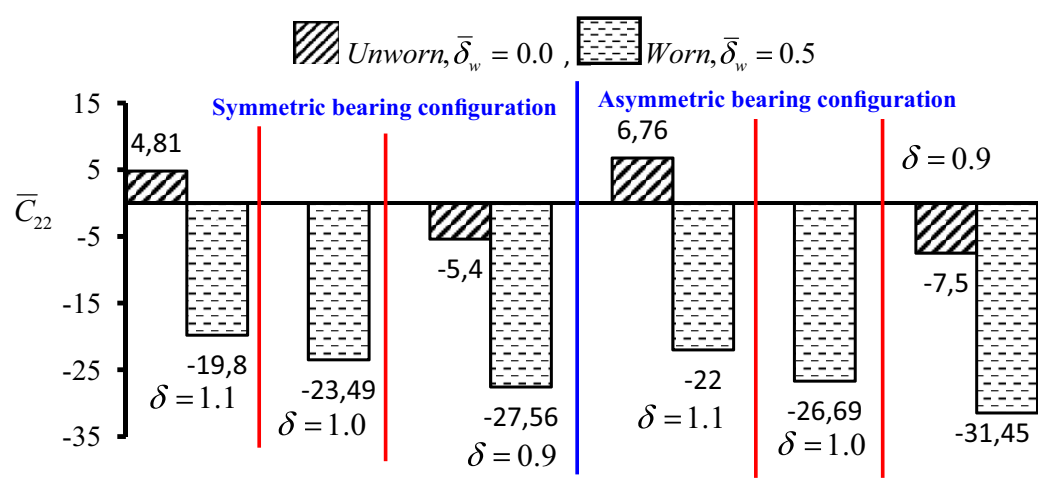

(d)

Fig. 11. (a) \% change in $\bar{h}_{\text {min }}$ for symmetric and asymmetric bearing configuration. (b) \% change in $\bar{\omega}_{\text {th }}$ for symmetric and asymmetric bearing configuration. (c) \% change in $\bar{S}_{22}$ for symmetric and asymmetric bearing configuration. (d) \% change in $\bar{C}_{22}$ for symmetric and asymmetric bearing configuration. 
loss caused by wear partially. Because of this, at offset factor $\delta=1.1$, the value of $\bar{S}_{22}$ gets increased to an order of $4.12 \%$ and $7.06 \%$ for both configurations of 2-lobe slot entry bearing respectively when compared to the unworn circular bearing. For the chosen values of $\bar{W}_{0}=1.3$ and $\delta=0.9$; it is observed that the value of $\bar{S}_{22}$ is lower for both 2-lobe slot entry bearing configurations. The decrease in the value of $\bar{S}_{22}$ is found to be more in symmetric bearing configuration when compared with asymmetric bearing configuration for chosen values of $\bar{W}_{0}$ and $\bar{\delta}_{\mathrm{w}}$. Further, it is seen that the value of $\bar{S}_{22}$ is largest for worn asymmetric bearing as compared to the symmetric 2-lobe slot entry bearing configuration.

\subsection{Direct fluid-film damping coefficient $\left(\bar{C}_{22}\right)$}

Figures $10 \mathrm{a}$ and $10 \mathrm{~b}$ show the variation in direct fluid-film damping coefficient $\left(\bar{C}_{22}\right)$ for symmetric and asymmetric 2-lobe slot entry journal bearing system respectively. It is noticed that the value of $\bar{C}_{22}$ increases for unworn symmetric journal bearing configuration. However, the value of $\bar{C}_{22}$ decreases when the value of $\bar{\delta}_{\mathrm{w}}$ increases. Further, a reduction in the value of $\bar{C}_{22}$ is observed for worn out bearing surface. In symmetric bearing configuration, the wear defect shows significant reduction in the value of $\bar{C}_{22}$ when compared with the asymmetric bearing configuration for the same operating condition.

As observed from Figure 10b, the tendency of asymmetric circular as well lobed slot restrictor bearing is to reduce the value of damping in the vertical direction $\left(\bar{C}_{22}\right)$ when subjected to influence of wear defect of $\bar{\delta}_{\mathrm{w}}=0.5$. The value of $\bar{C}_{22}$ is higher for asymmetric bearing configuration than that of symmetric bearing configuration for the chosen values of external load, $\bar{W}_{0}=1.3$ and $\bar{\delta}_{\mathrm{w}}=0.5$. Further, it is observed that the value of $\bar{C}_{22}$ increases with an increase in the value of $\delta$. From Figure 10b; it is clearly noticeable that the loss occurred in the value of direct damping $\bar{C}_{22}$ due to $\bar{\delta}_{\mathrm{w}}=0.5$ is partially compensated in both 2-lobe slot entry bearing configurations for the value of offset factor $\delta>1.1$. The results of the percentage change in the value of $\bar{C}_{22}$ for worn and unworn journal bearing have been presented in Figure 11d. It can be observed that the tendency of worn bearing $\left(\bar{\delta}_{\mathrm{w}}=0.5\right)$ is to reduce the value of $\bar{C}_{22}$ to the order of $19.8 \%$ and $22 \%$ respectively for both symmetric and asymmetric bearing configurations at the value of offset factor $\delta=1.1$. Further at the value of offset factor $\delta=1.1$, it is found that the value of $\bar{C}_{22}$ gets enhanced by $4.81 \%$ and $6.76 \%$ for both unworn symmetric slot entry restrictor and asymmetric slot entry restrictor bearing respectively.

\section{Conclusions}

In the present study, the influence of wear on the performance characteristics of 2-lobe slot entry journal bear- ing is investigated. Based on the numerically simulated results, the following salient conclusions are made:

1. The influence of wear defect substantially reduces the value of minimum fluid thickness $\left(\bar{h}_{\min }\right)$. The maximum reduction in the value of minimum fluid film thickness $\left(\bar{h}_{\min }\right)$ is found to be of the order of $21.56 \%$ for 2-lobe slot entry bearing configuration than that of circular slot entry bearing. Further, a reduction in $\bar{h}_{\text {min }}$ is also observed to be more in asymmetric 2-lobe slot entry bearing configuration than for symmetric 2-lobe slot entry bearing configuration.

2. The influence of worn defect deteriorates stability threshold speed margin $\left(\bar{\omega}_{\text {th }}\right)$ by $3 \%-9 \%$ and $1-6 \%$ for symmetric and asymmetric noncircular bearing configuration respectively. An increase in offset factor leads to a corresponding increase in stability threshold speed margin $\left(\bar{\omega}_{\text {th }}\right)$ of lobed slot entry bearing. A noncircular bearing configuration $(\delta>1.0)$ may provide improved value of stability threshold speed margin against circular slot entry bearing.

3. An increase in the wear depth parameter contributes towards a reduction in the values of stiffness $\left(\bar{S}_{22}\right)$ and damping $\left(\bar{C}_{22}\right)$ for symmetric bearing configuration. However; wear defect increases the fluid film stiffness $\left(\bar{S}_{22}\right)$ in asymmetric bearing configuration. Therefore, to compensate the loss in the value of stiffness $\left(\bar{S}_{22}\right)$ and damping $\left(\bar{C}_{22}\right)$ coefficients partially, a suitable configuration may be chosen from the following criteria:

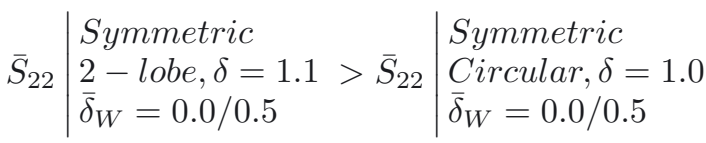

$$
\begin{aligned}
& >\bar{S}_{22} \mid \begin{array}{l}
\text { Symmetric } \\
2-\text { lobe }, \delta=0.9 \\
\bar{\delta}_{W}=0.0 / 0.5
\end{array}
\end{aligned}
$$

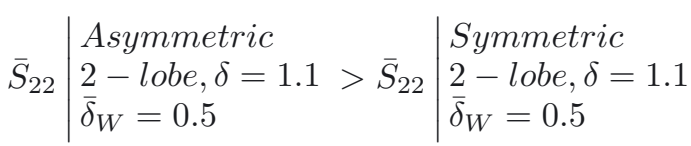

$$
\begin{aligned}
& \bar{C}_{22} \mid \begin{array}{l}
\text { Symmetric/Asymmetric } \\
2-\text { lobe }, \delta=1.1 \\
\bar{\delta}_{W}=0.0 / 0.5
\end{array} \\
& >\bar{C}_{22} \mid \begin{array}{l}
\text { Symmetric/Asymmetric } \\
\text { Circular, } \delta=1.0 \\
\bar{\delta}_{W}=0.0 / 0.5
\end{array} \\
& >\bar{C}_{22} \mid \begin{array}{l}
\text { Symmetric/Asymmetric } \\
2-\text { lobe, } \delta=0.9 \\
\bar{\delta}_{W}=0.0 / 0.5
\end{array}
\end{aligned}
$$

4. The stability of worn noncircular asymmetric bearing configuration $(\delta>1.0)$ is more than that of the unworn noncircular bearing configuration at higher operating external load. 


\section{References}

[1] C.W. Dee, G.L. Shires, The current state of the art of fluid bearings with discrete slot inlets, ASME J. Lubr. Technol. 2 (1971) 441-450

[2] K.J. Stout, W.B. Rowe, Externally pressurized bearingsdesign for manufacture part 1 - journal bearing selection, Tribol. Int. 7 (1974) 98-106

[3] W.B. Rowe, Advances in hydrostatic and hybrid bearing technology, Proc. IMechE Part C: J. Mech. Eng. Sci. 203 (1989) 225-242

[4] W.B. Rowe, D. Koshal, K.J. Stout, Slot-entry bearings for hybrid hydrodynamic and hydrostatic operations, J. Mech. Eng. Sci. 18 (1976) 73-78

[5] W.B. Rowe, D. Koshal, K.J. Stout, Investigation of recessed hydrostatic and slot-entry journal bearings for hybrid hydrodynamic and hydrostatic operation, Wear 43 (1997) 55-69

[6] D. Ives, W.B. Rowe, The performance of hybrid journal bearings in the super laminar flow regimes, Tribol. Trans. 35 (1992) 627-632

[7] Shangxian $\mathrm{Xu}$, Experimental investigation of hybrid bearings, Tribol. Trans. 37 (1994) 285-292

[8] S.C. Sharma, S.C. Jain, V. Kumar, R. Sinhasan, M. Subramanian, A study of slot-entry hydrostatic/hybrid journal bearing using the finite element method, Tribol. Int. 32 (1999) 185-196

[9] S.C. Sharma, S.C. Jain, N. Madhu Mohan Reddy, A study of non-recessed hybrid flexible journal bearing with different restrictors, Tribol. Trans. 44 (2001) 310-317

[10] S.C. Sharma, Nathi Ram, Influence of micropolar lubricants on the performance of slot-entry hybrid journal bearing, Tribol. Int. 44 (2011) 1852-1863

[11] O. Pinkus, Analysis of elliptical bearing, ASME Trans. 78 (1956) 965-973

[12] J.W. Lund, K.K. Thomsen, A calculation method and data for the dynamic coefficient of oil lubricated journal bearing, in: Proceedings ASME Design Engineering Conference (1001180), Chicago, USA, 1978, pp. 1-28

[13] S.P. Tayal, R. Sinhasan, D.V. Singh, Finite element analysis of elliptical bearings lubricated by a non-Newtonian fluid, Wear 80 (1982) 71-81

[14] P.K. Goenka, J.F. Booker, Effect of surface ellipticity on dynamically loaded cylindrical bearing, ASME J. Lubr. Technol. 105 (1983) 1-12

[15] M.K. Ghosh, M.R. Satish, Rotor dynamic characteristics of multi lobe hybrid bearings with short sills-part I, Tribol. Int. 36 (2003) 625-632

[16] M.K. Ghosh, A. Nagraj, Rotordynamic characteristics of a multilobe hybrid journal bearing in turbulent lubrication, Proc. IMechE Part J: J. Eng. Tribol. 218 (2004) 61-68

[17] A.D. Rahmatabadi, M. Nekoeimehr, R.Rashidi, Micropolar lubricant effects on the performance of noncircular lobed bearings, Tribol. Int. 43 (2010) 404-413
[18] V.M. Phalle, S.C. Sharma, S.C. Jain, Performance analysis of 2-lobe worn multirecess hybrid journal bearing system using different flow control devices, Tribol. Int. 52 (2012) 101-116

[19] J. Bouyer, M. Fillon, I. Pierre-Danos, Influence of wear on the behavior of a two- lobe hydrodynamic journal bearing subjected to numerous start ups and stops, ASME J. Tribol. 129 (2007) 205-208

[20] Prashant B. Kushare, Satish C. Sharma, A study of two lobe non recessed worn journal bearing operating with non-newtonian lubricant, Proc. IMechE Part J: J. Eng. Tribol. 227 (2013) 1418-1437

[21] Prashant B. Kushare, Satish C. Sharma, Nonlinear Transient Stability Study of Two Lobe Symmetric Hole Entry Worn Hybrid Journal Bearing operating with NonNewtonian Lubricant, Tribol. Int. 69 (2014) 84-101

[22] K.F. Dufrane, J.W. Kannel, T.H. McCloskey, Wear of Steam Turbine Journal Bearings at Low Operating Speeds, ASME J. Lubr. Technol. 105 (1983) 313-317

[23] H. Hashimoto, S. Wada, K. Nojima, Performance characteristics of worn journal bearings in both laminar and turbulent regime. Part 1: steady state characteristics, Tribol. Trans. 29 (1986) 565-571

[24] A. Kumar, S.S. Mishra, Steady state analysis of noncircular worn journal bearings in non-laminar lubrication regimes, Tribol. Int. 29 (1996) 93-498

[25] M. Fillon, J. Bouyer, Thermo hydrodynamic analysis of a worn plain journal bearing, Tribol. Int. 37 (2004) 129-136

[26] J.M. Redcliff, J.H. Vohr, Hydrostatic bearings for cryogenic rocket engine turbopumps, ASME J. Lubr. Technol. 91 (1969) 557-575

[27] I. Tokar, S. Alexandrov, Solution of a hydrostatic problem in turbulent motion of lubricant with allowance for shaft deformation and bearing wear, Trenie Iznos 10 (1989) 219-224

[28] F. Laurant, D.W. Childs, Measurement of rotor dynamic coefficients of hybrid bearings with (a) a plugged orifice (b) a worn land surface, J. Eng. Gas Turbines Power 124 (2002) 363-368

[29] E. Rajasekhar, S.C. Sharma, Performance Characteristics of Micropolar Lubricated Membrane-Compensated Worn Hybrid Journal Bearings, Tribol. Trans. 55 (2012) 59-70

[30] D. Dowson, A Generalized Reynolds Equation for Fluid Film Lubrication, Int. J. Mech. Eng. Sci. 4 (1962) 159170

[31] W.B. Rowe, S.X. Xu, F.S. Chong, W. Weston, Hybrid Journal Bearings with Particular Reference to Hole-Entry Configuration, Tribol. Int. 15 (1982) 339-348

[32] R.K. Awasthi, Satish C. Sharma, S.C. Jain, Performance of worn non-recessed hole-entry hybrid journal bearings, Tribol. Int. 40 (2007) 717-734

[33] S.C. Sharma, V. Kumar, S.C. Jain, R. Sinhasan, M. Subramanian, A Study of slot-entry hydrostatic/hybrid journal bearing using the finite element method, Tribol. Int. 32 (1999) 185-196 